\title{
Prevalence of hypoglycaemia in a random population after Roux-en-Y gastric bypass after a meal test
}

\author{
Marloes Emous ${ }^{1}$, Merel van den Broek¹, Ragnhild B Wijma', Loek J M de Heide', Gertjan van Dijk², Anke Laskewitz \\ Erik Totté ${ }^{1}$, Bruce H R Wolffenbuttel ${ }^{4}$ and André P van Beek ${ }^{1,4}$
}

${ }^{1}$ Centre for Obesity Northern-Netherlands (CON), Medical Centre Leeuwarden, Leeuwarden, The Netherlands

${ }^{2}$ GELIFES-Neurobiology, Department of Behavioral Neuroscience, University of Groningen, Groningen, The Netherlands ${ }^{3}$ Certe Laboratories, Medical Center Leeuwarden, Leeuwarden, The Netherlands

${ }^{4}$ Department of Endocrinology, University of Groningen, University Medical Centre Groningen, Groningen, The Netherlands

Correspondence should be addressed to M Emous: marloes.emous@znb.nI

\begin{abstract}
Objective: Roux-en-Y gastric bypass (RYGB) is an effective way to induce sustainable weight loss and can be complicated by postprandial hyperinsulinaemic hypoglycaemia (PHH). To study the prevalence and the mechanisms behind the occurrence of hypoglycaemia after a mixed meal tolerance test (MMTT) in patients with primary RYGB. Design: This is a cross-sectional study of patients 4 years after primary RYGB. Methods: From a total population of 550 patients, a random sample of 44 patients completed the total test procedures. A standardized mixed meal was used as stimulus. Venous blood samples were collected at baseline, every 10 min during the first half hour and every 30 min until $210 \mathrm{~min}$ after the start. Symptoms were assessed by questionnaires. Hypoglycaemia is defined as a blood glucose level below $3.3 \mathrm{mmol} / \mathrm{L}$. Results: The prevalence of postprandial hypoglycaemia was $48 \%$ and was asymptomatic in all patients. Development of hypoglycaemia was more frequent in patients with lower weight at surgery $(P=0.045)$, with higher weight loss after surgery $(P=0.011)$, and with higher insulin sensitivity calculated by the homeostasis model assessment indexes (HOMA2-IR, $P=0.014$ ) and enhanced beta cell function (insulinogenic index at $20 \mathrm{~min}$, $P=0.001)$.

Conclusion: In a randomly selected population 4 years after primary RYGB surgery, $48 \%$ of patients developed a hypoglycaemic event during an MMTT without symptoms, suggesting the presence of hypoglycaemia unawareness in these patients. The findings in this study suggest that the pathophysiology of $\mathrm{PHH}$ is multifactorial.
\end{abstract}

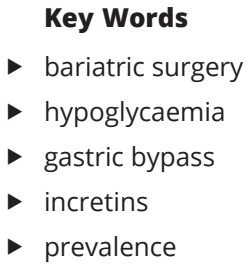

Endocrine Connections (2019) 8, 969-978

\section{Introduction}

The laparoscopic Roux-en-Y gastric bypass (RYGB) is often used to achieve sustained weight loss, resolve comorbidity and improve survival in patients with obesity (1).

It is an effective procedure, but unfortunately, it can be accompanied by long-term complications such as postprandial hyperinsulinaemic hypoglycaemia (PHH) $(2,3)$.
PHH typically occurs $1-3 \mathrm{~h}$ after a meal and can lead to autonomic and neuroglycopenic symptoms such as sweating, palpitations, hunger and drowsiness, which may even result in coma $(4,5,6)$. Studies have observed prevalence rates after primary gastric bypass surgery of $12 \%$ when assessed by means of questionnaires and up to $75 \%$ when assessed by continuous glucose monitoring https://ec.bioscientifica.com https://doi.org/10.1530/EC-19-0268

(c) 2019 The authors Published by Bioscientifica Ltd

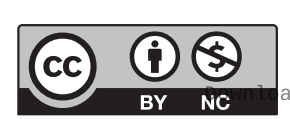

This work is licensed under a Creative Commons Attribution-NonCommercial 4.0 International License. ded from Bioscientifica.com at $04 / 26 / 2023$ 01:52:32PM 
systems (CGMSs) (7). Glucagon-like peptide-1 (GLP-1) is assumed to play a pivotal role in the pathophysiology of $\mathrm{PHH}$, most convincingly because the GLP-1 antagonist exendin (9-39) prevents postprandial hyperinsulinaemia and the subsequent hypoglycaemia in people with severe symptoms of late dumping $(8,9)$. Other gut hormones may also play a role after gastric bypass surgery such as peptide tyrosine tyrosine (PYY) in reducing appetite and suppressing pancreatic secretion and the vasoactive intestinal peptide (VIP) as a local neuromodulator released by intrinsic enteric neurons and responsible for the induction of intestinal gluconeogenesis through a VPAC1 receptor-dependent mechanism in enterocytes $(10,11,12)$. The role of these hormones in PHH is not clear $(12,13)$.

Although these studies have provided more insight into PHH, several (methodological) shortcomings should be mentioned. First of all, the questionnaires and symptom scales that were used for the assessment of the prevalence of PHH have not been validated. Further, these subjective methods do not take hypoglycaemic unawareness into account, a phenomenon that is described in patients with diabetes who have frequent episodes of hypoglycaemia (14). Diagnostic tools like CGMS have the advantage of monitoring glucose concentrations during daily activities, but the accuracy of CGMS in the hypoglycaemic range is poor $(15,16)$. Also, this method cannot be utilized to investigate the pathophysiology of PHH. Dynamic (or provocative) testing, however, can provide more insight into the pathophysiology, for instance, by providing a standardized stimulus or meal in a laboratory while performing extensive hormone analyses. Older studies have used the oral glucose challenge as standardized stimulus, but nowadays this is considered not physiological accurate; therefore, the mixed meal tolerance test (MMTT) is preferred (17). Smaller studies including up to \pm 20 patients using the MMTT after gastric bypass have been performed comparing patients with spontaneous severe hypoglycaemic symptoms to those without them $(18,19)$. These extremes of the spectrum of PHH have been informative, but do not allow a proper evaluation of the real prevalence of PHH and its main driving mechanisms in those with milder or no symptoms. For this purpose, a random selection of sufficient numbers of patients is necessary.

Therefore, we investigated the prevalence of $\mathrm{PHH}$ by venous sampling and by questionnaires during an MMTT in a random sample of patients with primary RYGB. Furthermore, to gain insight in the mechanisms provoking hypoglycaemia, we performed gut hormone analyses and assessed the beta-cell function and insulin resistance with several indices.

\section{Patients and methods}

\section{Study population}

Details on the study design were described previously (20). In brief, non-diabetic patients aged 18-75 years who underwent primary RYGB between 2008 and 2011 in our centre were eligible to participate in the study. A power analysis was performed and it revealed that a sample size of 50 patients was able to show a prevalence of at least $11 \%$ (based on an earlier study with self-reported symptoms of late dumping). From the entire cohort $(n=550)$, a random sample of 140 patients was drawn. All patients underwent an antecolic-antegastric Roux-en-Y reconstruction with a gastric pouch sized $30-60 \mathrm{~mL}$, a biliopancreatic limb length of $80 \mathrm{~cm}$ and an alimentary limb length of $150 \mathrm{~cm}$ (21). In total, 51 patients agreed to participate, but due to exclusion and withdrawal of consent, only 44 patients were analysed. The selection process, as well as reasons for exclusion, is shown in Fig. 1. One patient was registered as having a primary gastric bypass, but during the test, we found out she had gastric banding before, and so she was excluded from the analysis. The study protocol was approved by the Regionale Toetsingscommissie Patiëntgebonden Onderzoek Leeuwarden (local Medical Ethical Review Board) and all patients provided written informed consent. This study was conducted between February 2014 and March 2015.

\section{Study protocol}

All scheduled patients underwent the MMTT in the morning after an overnight fast of at least $8 \mathrm{~h}$. Anthropometric measures were obtained before the test meal and throughout the test. Via a peripheral intravenous cannula, blood samples were obtained before the meal $(t=0)$ and at 10, 20 and $30 \mathrm{~min}$ followed by every half hour until $210 \mathrm{~min}$ after the meal. Before the beginning of the test and at every $30 \mathrm{~min}$ until $210 \mathrm{~min}$ after the meal, patients filled in symptom-related questionnaires.

The mixed meal consisted of a $200 \mathrm{~mL}$ liquid nutrition supplement (Abbott Ensure S Plus) containing $300 \mathrm{kcal}$, $12.5 \mathrm{~g}$ protein, $40.4 \mathrm{~g}$ carbohydrate (of which $13.8 \mathrm{~g}$ is sugars), $9.84 \mathrm{~g}$ fat and $154.9 \mathrm{~g}$ water. The patients were asked to finish the meal within $10 \mathrm{~min}$.

\section{Blood analyses}

Venous blood for glucose and insulin analysis was collected in lithium-heparin tubes with a gel separator.

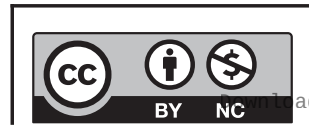

This work is licensed under a Creative Commons Attribution-NonCommercial 4.0 International License. ded from Bioscientifica.com at 04/26/2023 01:52:32PM 


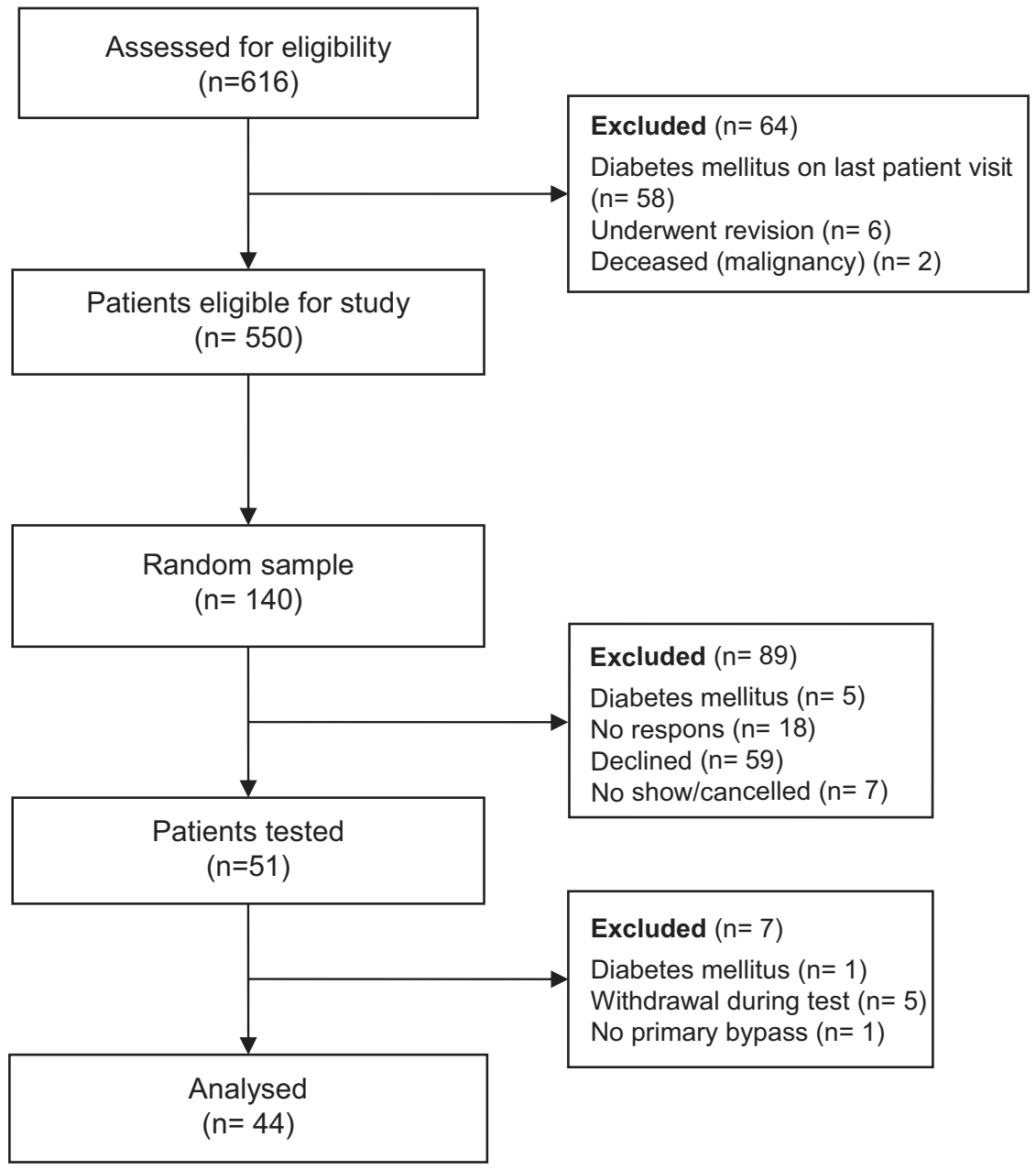

Figure 1

CONSORT flow diagram.
For the measurement of Peptide YY (PYY), VIP, active GLP-1 and inactive GLP-1, blood was collected in pre-cooled tubes containing $15 \%$ aprotonin; to this, $50 \mu \mathrm{L}$ dipeptidyl peptidase 4 (DPP-4) inhibitor (Merck Millipore DPP4-010) was added by injection through the cap directly prior to blood withdrawal without influencing the integrity of the pre-existing vacuum in the tube (22). All samples were centrifuged at $4^{\circ} \mathrm{C}$ and analysed immediately (glucose and insulin) or stored at $-80^{\circ} \mathrm{C}$ until analysed (GLP-1, VIP and PYY).

The glucose (hexokinase reaction) and insulin analyses (sandwich principle assay) were performed on a Roche Diagnostics Cobas analytical unit (glucose with 701 module; insulin with 801 module).

The concentrations of the active GLP-1, VIP, inactive GLP-1 and PYY were determined using commercial ELISA kits on a two-plate ELISA processing system (DS2, DYNEX Technologies, Chantilly, VA, USA), as per the manufacturer's instructions. The following commercial ELISA kits were used for the active form and inactive form of GLP-1: IBL International, Hamburg, Germany, code JP27784 and code JP27788. For human VIP: RayBiotech, Norcross, GA, USA, cat. \# EIA-VIP. For human PYY: Millipore Corporation, cat. \# EZHPYYT66K. For the active and inactive forms of GLP-1 and VIP, low- and high-level internal quality controls (QCs) were prepared by selecting and pooling plasma containing 15\% aprotonin and DPP-4 inhibitor (Merck Millipore DPP4-010). Low and high QCs for human PYY were provided by the manufacturer. The inter-assay variations of the low-level internal QC and the high-level internal QC were 57.0 and $43.7 \%$ for active GLP-1; 7.4 and $15.7 \%$ for inactive GLP-1; 62.0 and 54.1\% for human VIP and 12.1 and $17.2 \%$ for human PYY, respectively. Considering these variations, only within-subject changes from baseline were used for analysis. The maximum storage was 30 months. We did not analyse stability of the incretins, but we assume that with the precautions made (immediate storage), stability was warranted (22). 


\section{Questionnaire}

Symptoms were assessed during the MMTT with the dumping severity score (DSS) developed by Arts et al. This questionnaire is based on symptom pattern descriptions in the literature, using a four-point Likert scale (23). The patient is asked to grade the intensity $(0=$ absent; 1 =mild; 2 =moderate and 3 =severe, interfering with daily activities) of eight early-dumping symptoms (within $1 \mathrm{~h}$ after food ingestion) and six symptoms associated/attributed with/to hypoglycaemia (more than $1 \mathrm{~h}$ after food ingestion). These six hypoglycaemic symptoms are either adrenergic (sweating, palpitations, hunger, tremor) or neuroglycopenic (irritability, drowsiness) (23).

If patients rated three or more symptoms at an intensity 2 or 3 (i.e. moderate or severe, interfering with daily activities) on the DSS of which at least one was a neuroglycopenic symptom, this was considered a clinically relevant sign of postprandial hypoglycaemia based on previous research (21). To assess the psychological impact of these complaints, we also asked if this provoked anxiety or insecurity. In addition to the DSS, all patients were asked to report any other accompanying symptoms.

During the test, all patients were also observed for symptoms of hypoglycaemia by the researchers with open and specific questions and observation of physical evidence of symptoms (sweating, trembling, drowsiness, etc.).

\section{Definition of $\mathrm{PHH}$}

Patients were divided into two groups, a group with hypoglycaemia defined as a postprandial glucose concentration $<3.3 \mathrm{mmol} / \mathrm{L}$ and a group without hypoglycaemia defined by a postprandial glucose concentration $\geq 3.3 \mathrm{mmol} / \mathrm{L}$ in accordance with the guidelines (17). Symptomatic PHH was defined as hypoglycaemia in combination with a positive score on the DSS. Asymptomatic PHH was defined as hypoglycaemia without or with mild symptoms of neuroglycopenic or adrenergic symptoms.

\section{Calculations of beta-cell function and insulin sensitivity}

\section{In the fasting state}

The HOMA-IR was calculated as the product of fasting baseline levels of circulating glucose and insulin divided by $22.5\left(\right.$ Basal $_{\text {gluc }} \times$ Basal $\left._{\text {ins }} / 22.5\right)$ (24). The quantitative insulin sensitivity check index (QUICKI) was calculated by $1 /(\log ($ fasting insulin in $\mathrm{ng} / \mathrm{ml})+(\log ($ fasting glucose in $\mathrm{mg} / \mathrm{dL})(25)$. The HOMA- $\beta$ was calculated with fasting glucose and insulin concentrations using the HOMA2 calculator available at http://www.dtu.ox.ac.uk/ homacalculator/index.php.

\section{In the postprandial state}

Insulin resistance was calculated using the formula of the product of the area under the curves (AUCs) of the circulating glucose and insulin responses $\left(\mathrm{AUC}_{\text {gluc }} \times \mathrm{AUC}_{\mathrm{ins}}\right)$ as used during an OGTT (26).

Insulin sensitivity calculations were based upon the Matsuda Index (MISI) and was calculated as 10,000/ (square root of (fasting glucose $\times$ fasting insulin) $\times$ (mean glucose $\times$ mean insulin)) (27). The insulin secretion index (ISI) was calculated by dividing the total AUC for insulin at $60 \mathrm{~min}$ by the total AUC for glucose at $60 \mathrm{~min}$.

The $\beta$-cell sensitivity was calculated by three different methods. First, by the ratio of the AUCss of the circulating insulin and glucose responses $\left(\mathrm{AUC}_{\mathrm{ins}} / \mathrm{AUC}_{\text {gluc }}\right)(7,9)$. Secondly, by the liquid mixed meal tolerance disposition index (LMTT-DI), which was calculated according the following formula; MISI $\times$ ISI (10). Lastly, by the insulinogenic index calculated as the change in the insulin concentration at 10, 20 or 30 min versus baseline divided by the change in glucose in the corresponding time period.

\section{Statistical analysis}

Data are presented as mean ( \pm standard deviation), median (interquartile ranges (IQR)), frequencies or percentages, where appropriate.

In order to study the representativeness of the included study population, it was compared with the entire population and the random selection for age, sex, preoperative weight and preoperative comorbidities with the independent Student's $t$ tests and Fisher's exact tests.

Differences between the group with hypoglycaemia and the group without hypoglycaemia were assessed with $t$ tests (for continuous variables) or chi-square tests (for categorical variables). An alpha level of 0.05 was used for determining statistical significance. For graphical representations, the mean with the standard error of the mean are shown. All statistical analyses were performed using the Statistical Package for the Social Sciences (SPSS, Inc.), version 23. 


\section{Results}

\section{Demographic characteristics}

Data of 44 patients were available for analysis; 32 women and 12 men with a median age of 47 years (39-56); all demographic characteristics are presented in Table 1. The study population was representative of the entire surgical cohort $(n=550)$ in terms of age, sex, comorbidities before surgery, preoperative weight and postoperative weight at the time of the study (Table 2).

Patients who developed hypoglycaemia during the MMTT were more often female, had a shorter follow-up after surgery, had less often a history of type 2 diabetes, had a lower BMI and weight at the MMTT and had lost more (excess) weight after gastric bypass surgery (Table 1).

\section{Glucose and insulin}

Hypoglycaemia was present in 21 patients (48\%) occurring between 30 and $150 \mathrm{~min}$, but mostly between 60 and $120 \mathrm{~min}$ (Fig. 2). One patient started the MMTT with a fasting glucose concentration of $2.9 \mathrm{mmol} / \mathrm{L}$; this increased to $9.5 \mathrm{mmol} / \mathrm{L}$ at $20 \mathrm{~min}$ after the meal and after $60 \mathrm{~min}$, the patient had a hypoglycaemia with a nadir glucose concentration of $1.7 \mathrm{mmol} / \mathrm{L}$. Thirteen patients (30\%) developed hypoglycaemia with a nadir glucose concentration below $2.8 \mathrm{mmol} / \mathrm{L}$. Patients who developed a hypoglycaemic episode had significantly lower glucose values at baseline and on all time points after ingestion of the meal except for 10, 180 and $210 \mathrm{~min}$. Insulin concentrations were significantly higher at 10 and $30 \mathrm{~min}$ and significantly lower in the group with hypoglycaemia at baseline and in the late postprandial phase from 90 to $210 \mathrm{~min}$.

\section{Hypoglycaemia-related symptoms}

No differences in moderate or severe hypoglycaemic symptoms were seen between the group with hypoglycaemia versus the group without hypoglycaemia (Table 3).

In accordance with this, no symptoms of neuroglycopenia or adrenergic stimulation were observed by the investigators.

\section{Insulin sensitivity and beta-cell function}

All indices of insulin resistance showed that insulin sensitivity was significantly higher in the group with hypoglycaemia compared to the group without hypoglycaemia (Table 4).

In contrast, the HOMA2- $\beta$ was not different between the groups; the estimates of the postprandial betacell function showed an increased insulin secretion as calculated by the LMTT-DI and the insulinogenic index in the group with hypoglycaemia (Table 4).

Table 1 Comparison of patient characteristics between patients with and without hypoglycaemia.

\begin{tabular}{|c|c|c|c|}
\hline & Patients without hypoglycaemia $(n=23)$ & Patients with hypoglycaemia $(n=21)$ & $P$ value \\
\hline Age (years) & $48(42-56)$ & $42(39-56)$ & 0.449 \\
\hline Female $(\%)$ & $14(61)$ & $18(86)$ & 0.094 \\
\hline Time between surgery and study (months) & $54(44-58)$ & $43(38-53)$ & 0.010 \\
\hline \multicolumn{4}{|l|}{ Weight and weight loss } \\
\hline Weight at surgery (kg) & $143(128-157)$ & $130(120-147)$ & 0.045 \\
\hline BMI at surgery & $45(43-52)$ & $45(41-48)$ & 0.287 \\
\hline Weight at MMTT (kg) & $99(88-118)$ & 85 (79-94) & 0.001 \\
\hline $\mathrm{BMI}$ at MMTT & $32(30-39)$ & $29(26-32)$ & 0.014 \\
\hline EWL at MMTT (\%) & $62(48-76)$ & $78(64-92)$ & 0.011 \\
\hline TWL at MMTT (\%) & $28(22-34)$ & $33(27-41)$ & 0.036 \\
\hline \multicolumn{4}{|l|}{ Comorbidities preoperative } \\
\hline Type 2 diabetes & $13(57)$ & $1(5)$ & 0.000 \\
\hline Hypertension & $15(61)$ & $6(29)$ & 0.040 \\
\hline Dyslipidaemiaa & $6(26)$ & $3(14)$ & 0.462 \\
\hline \multicolumn{4}{|l|}{ Comorbidities postoperative } \\
\hline Type 2 diabetes ${ }^{b}$ & 0 & 0 & \\
\hline Hypertension & $6(26)$ & $4(19)$ & 0.902 \\
\hline Dyslipidaemia & $3(13)$ & $1(5)$ & 0.609 \\
\hline
\end{tabular}

Data are median and interquartile ranges (IQR), or numbers and frequencies (percentages). Bold indicates statistical significance.

aDefined as patients using lipid-lowering medication. ${ }^{\mathrm{b}}$ Exclusion criteria.

EWL, excess weight loss; MMTT, mixed meal tolerance test; TWL, total weight loss.

https://ec.bioscientifica.com

https://doi.org/10.1530/EC-19-0268 (c) 2019 The authors Published by Bioscientifica Ltd

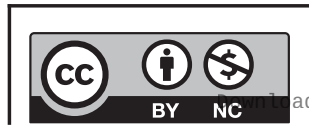

This work is licensed under a Creative Commons Attribution-NonCommercial 4.0 International License. ded from Bioscientifica.com at 04/26/2023 01:52:32PM via free access 
Table 2 Comparison between the sample and entire surgical cohort of patients who had undergone primary gastric bypass.

\begin{tabular}{l}
\hline \\
\hline Age (years) \\
Female (\%) \\
Comorbidities preoperative \\
Type 2 diabetes \\
Hypertension \\
Dyslipidaemia \\
Weight and weight loss \\
Weight at surgery (kg) \\
BMI at surgery \\
Last weight at outpatient clinic (kg) \\
Last BMl at outpatient clinic \\
EWL (\%) \\
TWL (\%)
\end{tabular}

\begin{tabular}{c}
\hline Sample $(N=44)$ \\
\hline $45.3(38.1-53.2)$ \\
$32(72.7)$ \\
$13(29.5)$ \\
$19(43.2)$ \\
$9(20.5)$ \\
$137(125-150)$ \\
$45(42-48)$ \\
$95.0(84.3-106.8)$ \\
$30(26-33)$ \\
$75(61-92)$ \\
$32(28-39)$
\end{tabular}

\begin{tabular}{c}
\hline Entire cohort $(N=506)$ \\
\hline $44.4(37.5-51.5)$ \\
$403(79.6)$ \\
$112(22.1)$ \\
$195(38.5)$ \\
$84(16.6)$ \\
$130(116-146)$ \\
$44(41-48)$ \\
$93.1(82.0-110.0)$ \\
$31(27-35)$ \\
$69(53-88)$ \\
$30(23-37)$
\end{tabular}

\begin{tabular}{c}
\hline $\boldsymbol{P}$ value \\
\hline 0.859 \\
0.332 \\
0.265 \\
0.629 \\
0.535 \\
\\
0.820 \\
0.097 \\
0.336 \\
0.746 \\
0.263 \\
0.625 \\
\hline
\end{tabular}

Data are median and interquartile ranges (IQR), or numbers and frequencies (percentages).

\section{Other intestinal hormones}

The concentrations of PYY, total GLP-1 and VIP measured as a percentage of change were not different between both groups (Fig. 3).

\section{Discussion}

In a random population 4 years after primary gastric bypass surgery, $48 \%$ of the patients developed a hypoglycaemic event $(<3.3 \mathrm{mmol} / \mathrm{L})$ without concurrent symptoms after a test meal. Patients who developed hypoglycaemia after a test meal were more often female and had lost more weight after their operation. In addition, they showed a higher insulin sensitivity (lower HOMA-IR and no prior history of type 2 diabetes) and an enhanced beta-cell function in the postprandial phase.

This is the first study consisting of a randomly selected, sufficiently large number of patients with a mid-term follow-up after primary gastric bypass surgery investigated with a dynamic test of sufficient duration. Previous studies have shown that the prevalence of $\mathrm{PHH}$ assessed with an oral glucose tolerance test varied between 10.4 and $80 \%$ depending on the glucose load (75 or $100 \mathrm{~g}$ ) and cut-off value $(2.8$ or $3.3 \mathrm{mmol} / \mathrm{L})$ and selection of the study population $(28,29,30,31,32)$.

The study by Raverdy et al. on the prevalence of PHH contains data 60 months after RYGB and found a prevalence of $7.9 \%$ of PHH (33). However, they used an OGTT and measured only at 30 and 120 min after oral ingestion with a definition of $\mathrm{PHH}$ as having a glucose value lower than $2.8 \mathrm{mmol} / \mathrm{L}$. We chose the MMTT as a provocation test as the composition of this liquid meal with a combination of fat, protein and $40 \mathrm{~g}$ of carbohydrate (of which $14 \mathrm{~g}$ is sugar) resembles a more normal food intake. To study the prevalence of $\mathrm{PHH}$ in a daily life setting, the MMTT is therefore a better test than the OGTT (17).

The first intriguing observation of our study is the high prevalence of $\mathrm{PHH}$ in combination with a total lack of related symptoms as reported by patients and as observed by the researchers. This phenomenon is known as hypoglycaemia unawareness or hypoglycaemia-associated autonomic failure (HAAF).
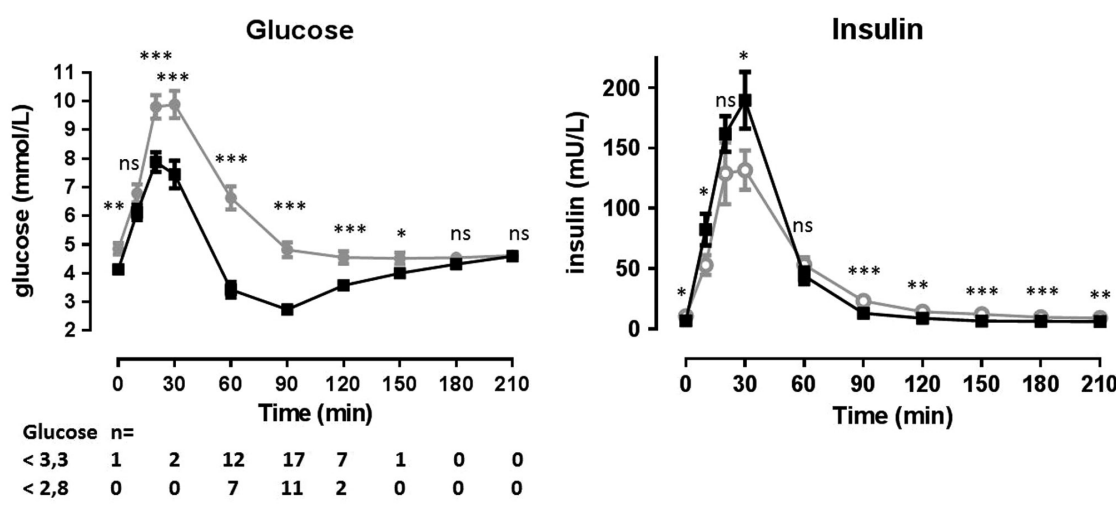

https://ec.bioscientifica.com https://doi.org/10.1530/EC-19-0268

(C) 2019 The authors Published by Bioscientifica Ltd

\section{Figure 2}

Glucose and insulin levels in patients with and without a hypoglycaemic event. Data are mean \pm S.E.M. $* P$ value $<0.05, * * P$ value $<0.01$, $\star * \star P$ value $<0.001$. Black line: patients without hypoglycaemia (glucose $>3.3 \mathrm{mmol} / \mathrm{L}$ ). Grey line: patients with hypoglycaemia (glucose $\leq 3.3 \mathrm{mmol} / \mathrm{L})$. 
Table 3 Number of patients with (moderate and severe) symptoms in patients with (+) and without (-) hypoglycaemia.

\begin{tabular}{l}
\hline Minutes after meal \\
\hline Hypoglycaemia \\
-15 \\
$60-90$ \\
$90-120$ \\
$120-150$ \\
$150-180$ \\
$180-210$ \\
\hline
\end{tabular}

\begin{tabular}{cc}
\hline \multicolumn{2}{c}{ Sweating } \\
\hline- & + \\
23 & 21 \\
0 & $1(5)$ \\
0 & 0 \\
0 & 0 \\
$1(4)$ & 0 \\
$1(4)$ & 0 \\
$1(4)$ & 0 \\
\hline
\end{tabular}

\begin{tabular}{cc}
\hline \multicolumn{2}{c}{ Palpitations } \\
\hline- & + \\
23 & 21 \\
0 & $1(5)$ \\
0 & 0 \\
0 & 0 \\
0 & 0 \\
0 & 0 \\
0 & 0 \\
\hline
\end{tabular}

\begin{tabular}{cc}
\hline \multicolumn{2}{c}{ Hunger } \\
\hline- & + \\
23 & 21 \\
$4(17)$ & $1(5)$ \\
$1(4)$ & $2(10)$ \\
$1(4)$ & $2(10)$ \\
$1(4)$ & $3(14)$ \\
$5(22)$ & $7(33)$ \\
$7(30)$ & $10(48)$ \\
\hline
\end{tabular}

\begin{tabular}{cc}
\hline \multicolumn{2}{c}{ Tremor } \\
\hline- & + \\
23 & 21 \\
$2(9)$ & $2(10)$ \\
0 & 0 \\
0 & 0 \\
0 & 0 \\
0 & $1(5)$ \\
0 & 0 \\
\hline
\end{tabular}

\begin{tabular}{cc}
\hline \multicolumn{2}{c}{ Drowsiness } \\
\hline- & + \\
23 & 21 \\
$1(4)$ & $1(5)$ \\
$2(9)$ & $4(19)$ \\
$2(9)$ & $2(10)$ \\
$3(13)$ & $2(10)$ \\
$2(9)$ & 0 \\
$1(4)$ & $1(5)$ \\
\hline
\end{tabular}

\begin{tabular}{cc}
\hline \multicolumn{2}{c}{ Irritability } \\
\hline- & + \\
23 & 21 \\
$1(4)$ & $1(5)$ \\
0 & 0 \\
0 & 0 \\
0 & 0 \\
0 & $1(5)$ \\
0 & $1(5)$ \\
\hline
\end{tabular}

Data are numbers and frequencies (percentages). No significances were observed between both groups.

It is frequently observed in people with type 1 diabetes on intensive insulin treatment who experience recurrent hypoglycaemia, but it has also been suggested to occur during PHH in the bariatric population (14). Our results are in line with Abrahamsson et al. who performed a stepwise hypoglycaemic clamp study in patients before and 23 weeks after gastric bypass surgery (34). They found that not only the hypoglycaemia symptom score, but also the levels of counter-regulatory hormone such as glucagon, cortisol and catecholamine as well as the sympathetic nerve responses were much lower after surgery compared to those before. One study investigated 15 RYGB patients without known hypoglycaemia by means of the CGMS and found that the patients had glucose concentrations below $3.3 \mathrm{mmol} / \mathrm{L} 2.9 \%$ of the time and $1.5 \%$ of the time, these concentrations dropped below $2.8 \mathrm{mmol} / \mathrm{L}$ (35). The patients were unaware of their hypoglycaemia four out of five (80\%) times. Thus, it is plausible that the high prevalence of hypoglycaemia as seen in our study translates in daily life as recurrent hypoglycaemia, leading to hypoglycaemia-induced autonomic failure and hypoglycaemia unawareness. This could also explain the discrepancy of the prevalence of
PHH measured during dynamic tests and by means of questionnaires.

Not only after gastric bypass surgery, but also in patients who underwent a vertical banded gastroplasty with $30 \%$ weight loss, a decrease in counter-regulation to hypoglycaemia has been observed (36). This suggests that the development of hypoglycaemia unawareness cannot be attributed to a specific type of bariatric surgery. The discrepancy between the asymptomatic low blood sugars in our study and the development of neuroglycopenia for which patients must be hospitalized in daily life is interesting and further research must clear this discrepancy of hypo-unawareness. The second main finding in the current study is the observation of differences in insulin sensitivity and insulin secretion between the groups with and without hypoglycaemia. The group with hypoglycaemia had in comparison with the group without hypoglycaemia a lower preoperative weight, more postoperative weight loss and were less likely to have a history of type 2 diabetes. All these are factors that are known to contribute to high insulin sensitivity. In our study, this was supported by lower fasting glucose and insulin concentrations and a lower HOMA2-IR.

Table 4 Differences in beta-cell function and insulin resistance.

\begin{tabular}{|c|c|c|c|}
\hline & No hypoglycaemia & Hypoglycaemia & $P$ value \\
\hline \multicolumn{4}{|c|}{ Insulin sensitivity } \\
\hline HOMA2-IR & $1.36(0.68-1.70)$ & $0.72(0.50-1.01)$ & 0.014 \\
\hline Quicki-index & $0.147(0.140-0.164)$ & $0.164(0.157-0.179)$ & 0.011 \\
\hline MISI & $4.3(3.0-7.8)$ & $7.8(4.7-12.0)$ & 0.014 \\
\hline ISI & $9.9(7.7-14.1)$ & $21.6(11.3-24.2)$ & 0.001 \\
\hline \multicolumn{4}{|c|}{ Beta cell function } \\
\hline HOMA2- $\beta$ & 121 (77-158) & 116 (99-137) & 0.685 \\
\hline LMTT-DI & $36.9(24.9-48.0)$ & $95.8(68.5-147.1)$ & 0.000 \\
\hline \multicolumn{4}{|c|}{ Insulinogenic index } \\
\hline $0-10 \mathrm{~min}$ & $21.0(10.8-43.4)$ & $41.4(23.1-62.9)$ & 0.012 \\
\hline $0-20 \mathrm{~min}$ & $19.7(12.8-29.0)$ & $43(25.3-64.1)$ & 0.001 \\
\hline $0-30 \mathrm{~min}$ & $19.1(14.0-34.7)$ & $44.6(26.6-66.5)$ & 0.600 \\
\hline
\end{tabular}

ISI, insulin secretion index; LMTT-DI, liquid mixed meal tolerance disposition index; MISI, Matsuda Index. Bold indicates statistical significance. 

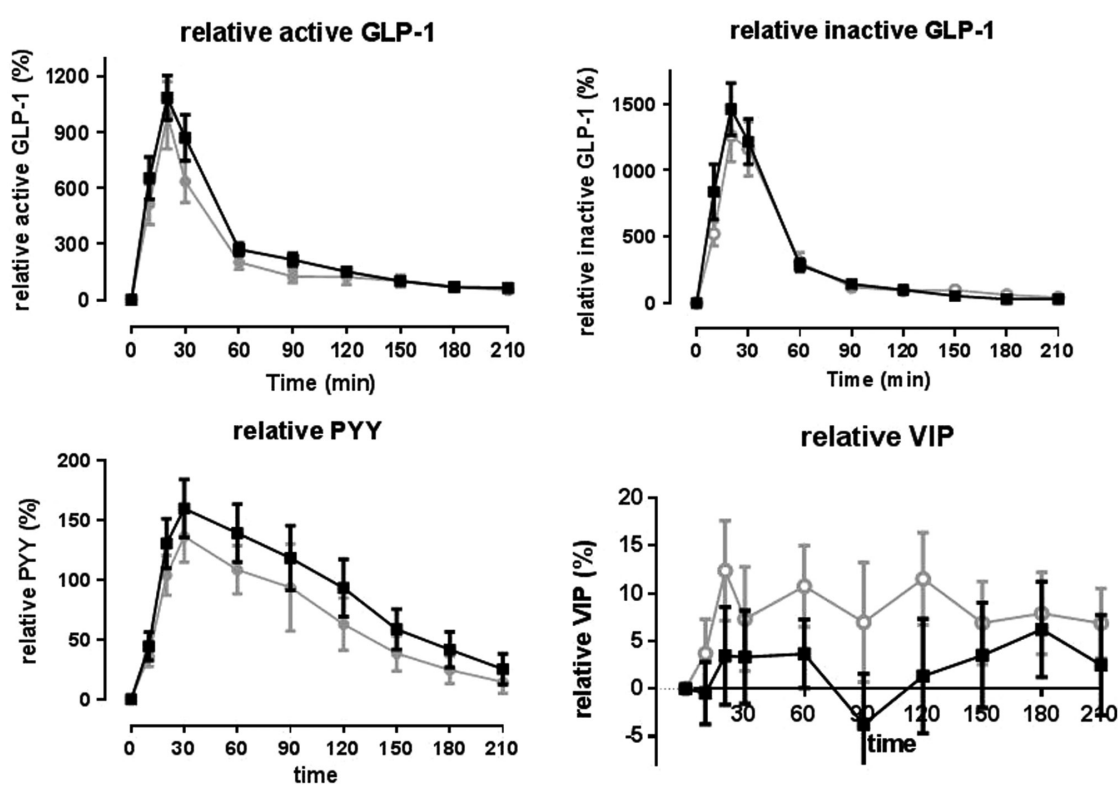

\begin{abstract}
Figure 3
Changes in gut hormones from baseline (percentage change) of various gut hormones in patients with and without a hypoglycaemic event. Data are mean \pm S.E.M. Black line: patients without hypoglycaemia (glucose $>3.3 \mathrm{mmol} / \mathrm{L}$ ). Grey line: patients with hypoglycaemia (glucose $\leq 3.3 \mathrm{mmol} / \mathrm{L})$
\end{abstract}

Also contributing is the increased insulin secretion in the first half hour of the test and the disposition index, which was indicative of an enhanced postprandial betacell function. Finally, the patients with a hypoglycaemic event returned to lower insulin levels at later time points. This could reflect higher insulin sensitivity. Our findings of higher insulin sensitivity and increased insulin secretion in patients with hypoglycaemia are in line with the prior studies $(14,28)$. One of these studies was by Guarino et al. They performed an OGTT in patients who were all diabetic preoperatively, but the majority (74\%) were at the time of testing postoperatively in remission (28). Also, Vaurs et al. found that the patients after RYGB with hypoglycaemia and during the OGTT had an increased insulin secretion rate in the first 15 min. Just as in the current study, these patients had lost more weight postoperatively and were less frequently diagnosed with diabetes before surgery. However, they did not observe a difference in insulin sensitivity between patients with and without hypoglycaemia (14). This discrepancy with the current study could be explained by the difference in the definition of hypoglycaemia, which was a glucose concentration $<2.8 \mathrm{mmol} / \mathrm{L}$ in Vaurs et al. and $<3.3 \mathrm{mmol} / \mathrm{L}$ in ours. However, it could also be caused by the difference in inclusion criteria, as they specifically included patients who experienced hypoglycaemic symptoms during daily life, while, in our current study, a random sample was drawn and none of the patients with hypoglycaemia during the MMTT had clinically relevant symptoms. A more rapid glucose peak and a higher GLP-1 response were found in patients with post-gastric bypass hypoglycaemia, suggesting a role for
GLP-1 in the pathophysiology $(28,37)$. Blocking the GLP-1-receptor by the GLP-1-receptor antagonist exendin (9-39) abolishes the occurrence of hypoglycaemia during an MMTT, providing further evidence for a role of GLP-1 in the pathogenesis of $\mathrm{PHH}$ (38). Interestingly, we did not find differences in the GLP-1, PYY and VIP concentrations between the group with hypoglycaemia versus the group without hypoglycaemia. Vaurs et al. also did not observe differences in GLP-1 (14). Difference in the stimulus, glucose versus a mixed meal, and the selection of patients could be the explanation for this discrepancy. Moreover, the lower glucose concentration, in the group with hypoglycaemia in our study, was already present in the fasting state, which suggests that the postprandial GLP-1 hypersecretion is not the only mechanism contributing to $\mathrm{PHH}$. This may be a consequence of a higher glucose sensitivity, but differences in hepatic glucose production by changes in glucagon concentrations or by changes in autonomic innervation have to be also considered. These mechanisms need to be studied further in detail.

The strength of our study is the random selection of patients with the cohort being comparable to the entire surgical cohort in terms of age, sex, comorbidities before surgery, preoperative weight and postoperative weight at the time of the study. Furthermore, we used an MMTT, which is more close to normal food intake compared to an OGTT.

Some limitations of the study must be mentioned. First, for various reasons, most unrelated to dumping, only 44 patients of the 51 patients in the random sample were tested, However, because most of these exclusions were due to problematic blood withdrawal, the risk of bias

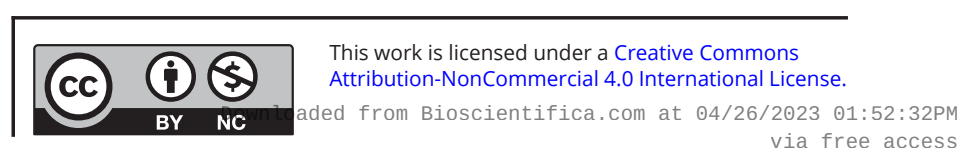


is low. The demographics of the tested patients were not different from the total group of operated patients, but there is still a possibility of selection bias.

Secondly, the test meal for an MMTT is not standardized, which is a general shortcoming of meal tests. Standardization should be recommended in order to compare studies in future research. Thirdly, patients were not tested before surgery and therefore other predictors beside the demographics cannot be extrapolated from our study. Pigeyre et al. found in nondiabetic patients after RYGB that a normal glucose tolerance test and a lower $\mathrm{HbA1c}$ before surgery were predictors of the hypoglycaemia during a $75 \mathrm{~g}$ OGTT 12 months after surgery (39). Finally, for GLP-1, PYY and VIP, only relative changes compared to the baseline could be presented due to the (unexpected) large inter-assay variation. Another limitation is the fact that no validated questionnaire for early and late dumping is available. The best-known questionnaire is the Sigstad score, which was initially developed as a clinical score for early dumping to be administered by a doctor. Later, some have used a modified Sigstad score as a patient questionnaire and had employed this in post-gastrectomy patients in case of ulcer disease $(32,40)$. It is not widely used for post-gastric bypass hypoglycaemia. As indicated earlier, the Edinburgh hypoglycaemia questionnaire is also not validated for late dumping. A potentially more useful and newer patient questionnaire is the DSS, developed by Arts and colleagues (23). This questionnaire is used for the evaluation of treatment responses in patients with post-gastric bypass hypoglycaemia. Validated cut-off levels are not available.

From clinical practice, we know that PHH can be provoked by physical activity. Physical activity can influence insulin sensitivity. In this study, we did not ask patients about their physical activity in the days before the test. Also, patients were tested without performing any physical activity. Future research also must focus on this aspect.

\section{Conclusion}

In a randomly selected population mid-term after primary RYGB surgery, $48 \%$ of patients developed a hypoglycaemic event during an MMTT. No hypoglycaemic symptoms accompanied these events suggesting the presence of hypoglycaemia unawareness in these patients. The findings in this study suggest that the pathophysiology of PHH is multifactorial.

\section{Declaration of interest}

The authors declare that there no conflict of interest that could be perceived as prejudicing the impartiality of the research reported.

\section{Funding}

This research project was funded by the scientific board of the Medical Center, Leeuwarden.

\section{References}

1 Colquitt JL, Picot J, Lovemen E \& Clegg AJ. Surgery for obesity. Cochrane Database of Systematic Reviews. 20092 CD003641. (https:// doi.org/10.1002/14651858.CD003641.pub3)

2 Abdeen G \& le Roux CW. Mechanism underlying the weight loss and complications of Roux-en-Y gastric bypass. Review. Obesity Surgery 201626 410-421. (https://doi.org/10.1007/s11695-015-1945-7)

3 Schauer PR, Bhatt DL, Kirwan JP, Wolski K, Brethauer SA, Navaneethan SD, Aminian A, Pothier CE, Kim ES, Nissen SE, et al. Bariatric surgery versus intensive medical therapy for diabetes - 3-year outcomes. New England Journal of Medicine 2014370 2002-2013. (https://doi.org/10.1056/NEJMoa1401329)

4 Kefurt R, Langer FB, Schindler K, Shakeri-Leidenmuhler S, Ludvik B \& Prager G. Hypoglycemia after Roux-en-Y gastric bypass: detection rates of continuous glucose monitoring (Cgm) versus mixed meal test. Surgery for Obesity and Related Diseases $201511564-569$. (https://doi.org/10.1016/j.soard.2014.11.003)

5 Kellogg TA, Bantle JP, Leslie DB, Redmond JB, Slusarek B, Swan T, Buchwald H \& Ikramuddin S. Postgastric bypass hyperinsulinemic hypoglycemia syndrome: characterization and response to a modified diet. Surgery for Obesity and Related Diseases 20084 492-499. (https://doi.org/10.1016/j.soard.2008.05.005)

6 Ukleja A. Dumping syndrome: pathophysiology and treatment. Nutrition in Clinical Practice 200520 517-525. (https://doi.org/10.117 7/0115426505020005517)

7 van Beek AP, Emous M, Laville M \& Tack J. Dumping syndrome after esophageal, gastric or bariatric surgery: pathophysiology, diagnosis, and management. Obesity Reviews 201718 68-85. (https://doi. org/10.1111/obr.12467)

8 Svane MS, Bojsen-Moller KN, Nielsen S, Jorgensen NB, Dirksen C, Bendtsen F, Kristiansen VB, Hartmann B, Holst JJ \& Madsbad S. Effects of endogenous GLP-1 and GIP on glucose tolerance after Roux-en-Y gastric bypass surgery. American Journal of Physiology: Endocrinology and Metabolism 2016310 E505-E514. (https://doi. org/10.1152/ajpendo.00471.2015)

9 Craig CM, Liu LF, Nguyen T, Price C, Bingham J \& McLaughlin TL. Efficacy and pharmacokinetics of subcutaneous exendin (9-39) in patients with post-bariatric hypoglycaemia. Diabetes, Obesity and Metabolism 201820 352-361. (https://doi.org/10.1111/dom.13078)

10 De Vadder F, Grasset E, Manneras Holm L, Karsenty G, Macpherson AJ, Olofsson LE \& Backhed F. Gut microbiota regulates maturation of the adult enteric nervous system via enteric serotonin networks. PNAS 2018115 6458-6463. (https://doi.org/10.1073/ pnas.1720017115)

11 Adrian TE, Long RG, Fuessl HS \& Bloom SR. Plasma peptide YY (PYY) in dumping syndrome. Digestive Diseases and Sciences 198530 1145-1148. (https://doi.org/10.1007/BF01314048)

12 Adrian TE, Savage AP, Sagor GR, Allen JM, Bacarese-Hamilton AJ, Tatemoto K, Polak JM \& Bloom SR. Effect of peptide YY on gastric, pancreatic, and biliary function in humans. Gastroenterology 198589 494-499. (https://doi.org/10.1016/0016-5085(85)90442-1)

13 Gomez G, Englander E \& Greeley G. Postpyloric Gastrointestinal Peptides. Physiology of the Gastrointestinal Tract, 5th ed., pp. 155-198. Cambridge, MA, USA: Academic Press, 2012.

14 Vaurs C, Brun JF, Bertrand M, Burcelin R, du Rieu MC, Anduze Y, Hanaire H \& Ritz P. Post-prandial hypoglycemia results from a nonglucose-dependent inappropriate insulin secretion in Roux-en-Y gastric bypassed patients. Metabolism 201665 18-26. (https://doi. org/10.1016/j.metabol.2015.10.020) 
15 Seaquist ER, Anderson J, Childs B, Cryer P, Dagogo-Jack S, Fish L, Heller SR, Rodriguez H, Rosebzweig J \& Vigerski R. Hypoglycemia and diabetes: a report of a workgroup of the American Diabetes Association and the Endocrine Society. Diabetes Care 201336 1384-1395. (https://doi.org/10.2337/dc12-2480)

16 Salehi M, Vella A, McLaughlin T \& Patti ME. Hypoglycemia after gastric bypass surgery: current concepts and controversies. Journal of Clinical Endocrinology and Metabolism 2018103 2815-2826. (https:// doi.org/10.1210/jc.2018-00528)

17 Emous M, Ubels FL \& van Beek AP. Diagnostic tools for post-gastric bypass hypoglycaemia. Obesity Reviews 201516 843-856. (https:// doi.org/10.1111/obr.12307)

18 Laurenius A, Werling M, Le Roux CW, Fandriks L \& Olbers T. More symptoms but similar blood glucose curve after oral carbohydrate provocation in patients with a history of hypoglycemia-like symptoms compared to asymptomatic patients after Roux-en-Y gastric bypass. Surgery for Obesity and Related Diseases 201410 1047-1054. (https://doi.org/10.1016/j.soard.2014.04.007)

19 Salehi M, Gastaldelli A \& D'Alessio DA. Altered islet function and insulin clearance cause hyperinsulinemia in gastric bypass patients with symptoms of postprandial hypoglycemia. Journal of Clinical Endocrinology and Metabolism 201499 2008-2017. (https://doi. org/10.1210/jc.2013-2686)

20 Wijma RB, Emous M, van den Broek M, Laskewitz A, Kobold ACM \& van Beek AP. Prevalence and pathophysiology of early dumping in patients after primary Roux-en-Y gastric bypass during a mixed-meal tolerance test. Surgery for Obesity and Related Diseases 201815 73-81. (https://doi.org/10.1016/j.soard.2018.10.004)

21 Emous M, Wolffenbuttel BHR, Totte E \& van Beek AP. The short- to mid-term symptom prevalence of dumping syndrome after primary gastric-bypass surgery and its impact on health-related quality of life. Surgery for Obesity and Related Diseases 201713 1489-1500. (https:// doi.org/10.1016/j.soard.2017.04.028)

22 Wewer Albrechtsen NJ, Bak MJ, Hartmann B, Christensen LW, Kuhre RE, Deacon CF \& Holst JJ. Stability of glucagon-like peptide 1 and glucagon in human plasma. Endocrine Connections 20154 50-57. (https://doi.org/10.1530/EC-14-0126)

23 Arts J, Caenepeel P, Bisschops R, Dewulf D, Holvoet L, Piessevaux H, Bourgeois S, Sifrim D, Janssens J \& Tack J. Efficacy of the long-acting repeatable formulation of the somatostatin analogue octreotide in postoperative dumping. Clinical Gastroenterology and Hepatology 2009 7 432-437. (https://doi.org/10.1016/j.cgh.2008.11.025)

24 Hill NR, Levy JC \& Matthews DR. Expansion of the homeostasis model assessment of beta-cell function and insulin resistance to enable clinical trial outcome modeling through the interactive adjustment of physiology and treatment effects: iHOMA2. Diabetes Care 201336 2324-2330. (https://doi.org/10.2337/dc12-0607)

25 Katz A, Nambi SS, Mather K, Baron AD, Follmann DA, Sullivan G \& Quon MJ. Quantitative insulin sensitivity check index: a simple, accurate method for assessing insulin sensitivity in humans. Journal of Clinical Endocrinology and Metabolism 200085 2402-2410. (https:// doi.org/10.1210/jcem.85.7.6661)

26 McAuley KA, Williams SM, Mann JI, Walker RJ, Lewis-Barned NJ, Temple LA \& Duncan AW. Diagnosing insulin resistance in the general population. Diabetes Care 200124 460-464. (https://doi. org/10.2337/diacare.24.3.460)

27 Matsuda M \& DeFronzo RA. Insulin sensitivity indices obtained from oral glucose tolerance testing: comparison with the euglycemic insulin clamp. Diabetes Care 199922 1462-1470. (https://doi. org/10.2337/diacare.22.9.1462)
28 Guarino D, Moriconi D, Mari A, Rebelos E, Colligiani D, Baldi S, Anselmino M, Ferrannini E \& Nannipieri M. Postprandial hypoglycaemia after Roux-en-Y gastric bypass in individuals with type 2 diabetes. Diabetologia 201962 178-186. (https://doi. org/10.1007/s00125-018-4737-5)

29 Kim SH, Liu TC, Abbasi F, Lamendola C, Morton JM, Reaven GM \& McLaughlin TL. Plasma glucose and insulin regulation is abnormal following gastric bypass surgery with or without neuroglycopenia. Obesity Surgery 200919 1550-1556. (https://doi.org/10.1007/s11695009-9893-8)

30 Roslin MS, Oren JH, Polan BN, Damani T, Brauner R \& Shah PC. Abnormal glucose tolerance testing after gastric bypass. Surgery for Obesity and Related Diseases 20139 26-31. (https://doi.org/10.1016/j. soard.2011.11.023)

31 van der Kleij FGH, Vecht J, Lamers CBHW \& Masclee AAM. Diagnostic value of dumping provocation in patients after gastric surgery. Scandinavian Journal of Gastroenterology 199631 1162-1166. (https://doi.org/10.3109/00365529609036905)

32 Paik CN, Choi M-G, Lim CH, Park JM, Chung WC, Lee K-M, Jun K-H, Song KY, Jeon HM, Chin H-M, et al. The role of small intestinal bacterial overgrowth in postgastrectomy patients. Neurogastroenterology and Motility 201123 e191-e196. (https://doi. org/10.1111/j.1365-2982.2011.01686.x)

33 Raverdy V, Baud G, Pigeyre M, Verkindt H, Torres F, Preda C, Thuillier D, Gele P, Vantyghem MC, Caiazzo R, et al. Incidence and predictive factors of postprandial hyperinsulinemic hypoglycemia after Roux-en-Y gastric bypass. Annals of Surgery 2016264 878-885. (https://doi.org/10.1097/SLA.0000000000001915)

34 Abrahamsson N, Borjesson JL, Sundbom M, Wiklund U, Karlsson FA \& Eriksson JW. Gastric bypass reduces symptoms and hormonal responses in hypoglycemia. Diabetes 201665 2667-2675. (https:// doi.org/10.2337/db16-0341)

35 Abrahamsson N, Eden Engstrom B, Sundbom M \& Karlsson FA. Hypoglycemia in everyday life after gastric bypass and duodenal switch. European Journal of Endocrinology 2015173 91-100. (https:// doi.org/10.1530/EJE-14-0821)

36 Guldstrand M, Ahren B, Wredling R, Backman L, Lins PE \& Adamson U. Alteration of the counterregulatory responses to insulin-induced hypoglycemia and of cognitive function after massive weight reduction in severely obese subjects. Metabolism 200352 900-907. (https://doi.org/10.1016/S00260495(03)00103-3)

37 Goldfine AB, Mun EC, Devine E, Bernier R, Baz-Hecht M, Jones DB, Schneider BE, Holst JJ \& Patti ME. Patients with neuroglycopenia after gastric bypass surgery have exaggerated incretin and insulin secretory responses to a mixed meal. Journal of Clinical Endocrinology and Metabolism 200792 4678-4685. (https://doi.org/10.1210/ jc.2007-0918)

38 Salehi M, Gastaldelli A \& D'Alessio DA. Blockade of glucagon-like peptide 1 receptor corrects postprandial hypoglycemia after gastric bypass. Gastroenterology 2014146 669.e2-680.e2. (https://doi. org/10.1053/j.gastro.2013.11.044)

39 Pigeyre M, Vaurs C, Raverdy V, Hanaire H, Ritz P \& Pattou F. Increased risk of OGTT-induced hypoglycemia after gastric bypass in severely obese patients with normal glucose tolerance. Surgery for Obesity and Related Diseases 201511 573-577. (https://doi. org/10.1016/j.soard.2014.12.004)

40 Svennevig JL, Vetvik K, Bernstein O \& Sigstad H. Dumping following partial gastrectomy. Annales Chirurgiae and Gynaecologiae 197766 4-7.

Received in final form 2 June 2019

Accepted 12 June 2019

Accepted Preprint published online 12 June 2019 https://ec.bioscientifica.com https://doi.org/10.1530/EC-19-0268 (c) 2019 The authors Published by Bioscientifica Ltd

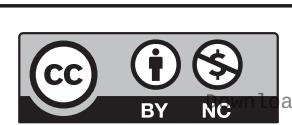

This work is licensed under a Creative Commons Attribution-NonCommercial 4.0 International License. ded from Bioscientifica.com at 04/26/2023 01:52:32PM 